\title{
The Barriers and Strategies of Communication among Student Nurses during Cross-Cultural Nursing Care Practice
}

\author{
Nur Lailatul Masruroh* and Reni Ilmiasih \\ Departement of Nursing, Faculty of Health Science, University of Muhammadiyah Malang, Indonesia \\ Jalan Bendungan Sutami 188A, Kota Malang, Jawa Timur, 65145 \\ *Corresponding author: faranurlailatul@yahoo.com
}

\begin{abstract}
Background: Communication is a very essensial aspect of cross-culture care nursing practice. Nurses will meet some obstacles in the situations where they do not communicate as their patients language, and it will lead to the poor quality of nursing care. Objective: The purpose of the study is to explore the student nurses' experiences in communication during the cross-culture care nursing practice in a general hospital. Method: The design is qualitative descriptive exploratory study. Semi structured interviews and open questioner were conducted with eight students nurses from Indonesia and Thailand. The data were analyzed thematically. Result: There are three themes that emerge as the findings of the study, these are: the barriers of communication, the strategies of communication and factors affecting communication. Conclusion: Students nurses have made creative startegies to communicate with the patients who have different background of culture. It is important for every school of nursing to ensure that the prospective of nurses has been completed with sufficient knowledge and skill of cross-culture communication. It is in order to give high quality of nursing care for the patients from the different cultural and guarantee the readiness of nurses in facing the challenge of ASEAN Community.
\end{abstract}

Keywords : Student Nurses, Communication, Cross-Cultural Nursing Care

\section{INTRODUCTION}

ASEAN Community that has been launched in 2015 have bring the impact to the health care delivery system, it is including nursing. Nurses will face particular challenges when take care for the patients from a different cultural background (Potter and Perry, 2008). Understanding cultural differences is both an opportunity and a challenge to professional nursing practice. The ability to overcome the challenges of understanding a new culture allows the nurse be able to provide a higher quality of nursing care through an improved nurse-client relationship and achieve the goal of improved nursing practice (Hitchcock, 1999) as the prospective of nurse, it is essessensial for every student nurses to be able to adapt their nursing care strategies to respond to the culture need of their patients, and it will be the faculty members` responsibility to help to close the gap between academic preparation and the diverse work environtment (Kratzke and Bertolo, 2013).

The definition of culture is the shared beliefs, values, ideas, language, communication and norm of a group of people (Giger, 2017). The common problem of nurses and other healthcare professionals is lacking the knowledge and skills to respond to the needs of patient from a different cultural background to their own (Berlin et al , 2006 ; Gerrish et al, 1996), and the major barrier in the cross-culture care is communication difficulties (Cioffi, 2013). Communication is a fundamental part of nursing. It involves sharing information, caring conversations and social interactions. Communication is a significant factor with 
regard to patient satisfaction and the quality nursing care (Potter and Perry, 2008). Nurses mentioned as the fundamental part to improve patient experiences of the quality of nursing care. Patients' emphasize that nurses should take time to communicate since it is through communication that nurses get to know patients, identify their needs and inform them. When communication is poor patients are dissatisfied with their care (Kieft et al, 2014)

Moreover, in case of chronic illness for example like Heart Failure, the complex problem will obviously reluctant if poor communication can not be avioided between nurse and patient. This uncertainty relates to understanding of the implications of their diagnosis, appropriate treatments, and when and how to seek effective help. Health professionals agree this is a major problem but feel they lack knowledge, opportunities, or adequate support to improve the situation. Fragmented care with lack of coordination and poor communication makes life becoming more difficult (Browne et al, 2014).

Accordingly, the ability to develop the skill to communication effectively is something important in the cross-culture care. Therefore, it is important to explore deeply the phenomena that will be the focus of investigation within the study which entitled the experiences of student nurses in communication during the cross-cultural learning .

\section{METHOD}

The overall objective of this study is to explore the student nurses experiences in communication during the cross-cultural learning program. Descriptive exploratory qualitative was used to investigate the topics under investigation. The present research design will help to explore the dimensions of the problem because there is limited knowledge about the research issue (Straus and Corbin, 1998).

Participants for this research were purposefully selected because they all had particular experience of the topic which the researcher is trying to explore and who following requirement of inclusion criteria (Holloway and Wheeler, 2010). Semi-structured interviews and open questioners were given to 8 student nurses, four student nurses were from Indonesia and the rest were from Thailand. All of students spoke English as the daily conversation among them during the nursing practice. However, normally each of student was used to spoke in their national language as the everyday language among students who have the same nationality. As an additional information, especially for the Indonesian students were come from different background of ethnicity. It is important to be noted since each of ethnic in Indonesia is typically using different local languages.

The participants were from nursing study program of a famous University in Thailand and also a Private University in East Java, Indonesia and had undertaken the students exchange program and conducted a nursing parctice in a general hospital in Malang City, East Java Province of Indonesia. The general information of the participants are shown in Table 1.

The interviewing process were conducted in English and it took place and time based on the agreement of both interviewer and participants during the cross-cultural learning program. The researcher asked the same main questions, that is: "would you please tell me about your experiences in communication during undertake the cross-cultural nursing care practice!". The data were collected by a written open question and also in depth Interviews. The result of interviews were audio-tape recorded and labeled with the number or code, date and an anonymous name to protect the identity of each participant. All the answers of participants were transcribed after each of collecting data process, and the data deleted afterwards. The data collection process was ended when the saturation of the data is achieved. It was achieved in the sixth participant. However, the collecting data process was 
continued until two more participants in order to ensure that there is no new information anymore (Holloway and Wheeler, 2010 ; Polit and Beck, 2012).

Table 1 Description of participants by initial, gender, age, race/ ethnic and nationality

\begin{tabular}{llllll}
\hline Initial & Gender & Age & Year of Study & Ethnicity & Nationality \\
\hline UB & F & 22 & 3th Year & Thai & Thailand \\
NP & F & 21 & 3th Year & Thai & Thailand \\
AJ & F & 21 & 3th Year & Thai & Thailand \\
BR & F & 21 & 3th Year & Thai & Thailand \\
RN & F & 22 & 4th Year & Lombok & Indonesia \\
TM & F & 22 & 4th Year & Sumbawa & Indonesia \\
C & M & 24 & 4th Year & Central Java & Indonesia \\
YA & M & 23 & 4th Year & Bima & Indonesia \\
\hline
\end{tabular}

In order to have a deep understanding of the data, the researcher read through the transcribed interviews three times. Next, the researcher established initial code (open source) on the data (Holloway and Wheeler, 2010). In this step, the researcher wrote a brief, and started with the words used by participant to prevent researcher from imposing her own framework and ideas from the data. Most of codes were generated from the data are chunks of the data that represented the main idea of each participant's statement. Subsequently, to find supporting evidence and identify the similar meanings which are linked to the same phenomenon, the following step was grouping the codes together which reflect every different significant idea (Holloway and Wheeler, 2010 ; Polit and Beck, 2012).

Next, the researcher focused on the most frequent codes, sorted and compared amounts of data from these focused codes to generate categories and themes (Charmaz, 2006). In formulating the themes and sub themes, researcher integrated quotations from the transcript of the interview to describe the experience explicitly. At this stage, the researcher identified several themes that appeared as a result of exhaustive analysis of the data.

Two activities were taken to develop credibility in this study. Firstly, the researcher established initially familiarity with the culture of participants before the first data collection take place. Secondly, the researcher gave an opportunity to refuse to participate in the study to ensure that the data collection process involve only those who are indeed willing to participate and prepared the data objectively (Shenton, 2004). Meanwhile, transferability ascertains with thick description, and dependability and confirmability are achieved with collected the data using semi-structured interviews on competent participants who are knowledgeable and answering essentially the same questions (Shenton, 2004). Next, audit trail is performed to ensure confirmability by writing the detailed process of how researcher achieved the conclusions (Holloway and Wheeler, 2010 ; Polit and Beck, 2012).

\section{RESULT AND DISCUSSION}

The student nurses`experiences in communication during the cross-cultural learning programpresented through three themes that emerged from the data. Those are: the barriers of communication, the strategies of communication and factors affecting communication. 


\section{The barriers of communication}

The barriers in the language lead to the problems for nurses and patients. Problems ware not only felt by the Thai student nurses, but also the student nurses from Indonesia since in general they come fro the different ethnic background with the patients. Despite, the difficulties that has been felt by Indonesian Students did not as hard as perceived by Thai students. Participants expressed concern that they felt uncomfortable in providing limited information when they have to explain the procedure to the patient who has East Javanese background. In fact, they feel that they generally communicate the technical aspects of what the procedure requires, an explanation of the reasons why the procedure needs frequently have been eliminated because of the limitation of communication. A student nurse explained the obstacles she had :

"We couldn't speak fluently, it didn't feel right but I don't know what to say...the patient didn't get my point why I needed to change the dressing with the new one and I didn't really satisfy to explain it either. It was more that I just did my job and... I just change it ..."

Another situations were emerged from the experience of participants who felt that an important thing of the caring relationship was disappeared :

"There is something that missing during the nursing care... when I get into contact with the patient, It's not organized very well...it's difficult to say something nice to make them happy and close ...when you don't have a way to communicate...communication is essential for good nursing care..."

\section{The strategies of communication}

There are many strategies that participants used to developed communication with patients in situations where they did not understand the common spoken language. All of participants from Thailand concluded opinion on how important the existence of their Indonesian friends who became a partner during nursing practice. The Indonesian student nurses always facilitated the language barrier of the Thai students. Meanwhile, in such situations, Indonesian students also need a help from the nurses to translate the local language when they faced patients who did not understand the national language.

"Fortunatelly, my Indonesian partner always help me to translate Bahasa into

English...It supports me a lot during communication with the patient.."

The national language of Indonesian is Bahasa, however the most daily conversation of the people are using the local language in line with their ethnicity background. In general, the patients background ethnicity are East Javanese, which typically tend to more rugged compared to the common Java language which is derived from the other Javanese ethnicity. Therefore, several participants described situations in which they had made an intentional effort to facilitate communication. For example, they had learnt a few words in the patient's language, and it also including the Indonesian students.

"I learnt how to say greeting, sorry and thank you in Javanese language...my friend also told me how to call someone by the gender and seniority in the Javanese manner...in such moment..it help me a lot"

Meanwhile, the Indonesian student nurses also learn how to speak in the high level of Java language. It is the common rule prevailing during speaking to someone older or respected. 
"I have been stay more than 3 years in this town...but I still need time to understand the high level of Java Language..it is completely different with mine... when you don't know how to speak properly, people will accuse you as an impolite.."

Participants also emphasized the advantages of using body language as a means of communication when there was no common spoken language.

"...we know that $70 \%$ of communication is body language so why don't we use it; it is a good tool for communication.. we can use body language instead and a smile..."

\section{Factors affecting communication}

It was clear that there were other factors which affect communication in cross-cultural nursing care practice. Participants varied in their attitude towards overcoming communication difficulties. Participants who were from Thai background generally emphasized the benifits of adopting a positive attitude towards addressing communication problems.

"If you take your time and are interested in the patient then you can understand them" Most participants emphasized on how important to understand the different cultural norms and traditions. It supports them to appreciate that people behave differently and have different world views. Cultural knowledge gave them more confidence in tackling unfamiliar situations which in turn led to improved communication.

"You have a different attitude, you have learnt how to handle...different situations. You have learnt how to think in a different way..."

Most of participants suggested that their experience within the cross-cultural learning program had made them culturally aware and had helped them to see the individual and not just the cultural group they belonged to. It also helped them be comfortable with meeting patients from different cultural backgrounds.

"I have so much experience due to my background. Somehow it comes automatically and then...you cross a line, in the end you don't see cultural differences but individual ones"

The results reported in this study are from an exploratory study of student nurses experiences in communication during the cross-cultural learning program, particularly in the nursing care practice session. In accordance with In agreement with the literatures (Leininger and McFarland, 2002 ; Giger, 2017). Student nurses identified that effective communication was fundamental to providing quality nursing care. However, they experienced the difficulties when trying to communicate with patients when they did not speak the same language. Other authors have identified the anxiety nurses experience when they are unable to communicate effectively with patients and this observation is endorsed by student nurses in the current study (Kai et al, 2007 ; Seale et al, 2013; Kratzke and Bertolo, 2013 ; Xiao et al, 2013). Kai et al (2007) identified the professional uncertainty and disempowerment that qualified nurses and other healthcare professionals experience in cross-cultural care encounters due to a perceived ignorance of cultural differences.

Student nurses in the current study identified how cultural knowledge acquired through their cross-cultural learning nursing program had helped to equip them with an understanding of cultural diversity that could inform their interactions with patients from different cultural backgrounds. However, they lacked skills and confidence in applying knowledge to practice when assessing patients' needs and were anxious about causing offence through their line of questioning. Medical students in the UK and also Students 
nurses from Southwestern University report similar challenges in cross-cultural care encounters. The current study points to the limitations of the student nurses in communication skills but shows a high motivation to learn more (Kai, 2001 ; Kratzke and Bertolo, 2013).

Gerrish et al (2001) have identified how nurses can work towards ensuring effective and sensitive communication in cross-cultural care encounters. There are many factors that contributes to the ability of nursing students in developing the effective and sensitive communication in cross-cultural situation, the younger the students, the less exposure to society they have had; therefore younger students have fewer concerns regarding social issues, such as employment opportunity and the disparity of salary and resources related to the care of older people, when compared with older students. Furthermore, working experience of the students will also leads to the quality of cross-culture communication. Moreover, some studies show that the essential part from the responses included the relevance of cultural knowledge, cultural awareness including acknowledgement of their biases, and cooperation among cultures with cultural desire. The result of some studies also showed that engaging students first hand with a new cultural group in a class simulation exercise was essenfial to enhance their cultural competence. Students learned how their attitudes may influence their perceptions about cultural differences (Kratzke and Bertolo, 2013 ; Xiao et al, 2013).

\section{CONCLUSION}

The implications of the findings of this study could be the reference in developing the nursing curriculum that emphasizes on enhancing the ability of cross-culture communication skill and knowledge. Many challenges in the cross-culture communication that have been faced by students nurses during the program, especially when they do not use the same language with the patient. Although they use many strategies to facilitate communication they find themselves in situations where they are unable to communicate effectively and this leads to dissatisfaction with the caring experience. They also lack skills and confidence in cross-cultural communication. Even in situations where students felt satisfied that they were able to communicate, it does not mean that the patient was satisfied with the interaction. In the light of these findings, is important that nursing programs enable student nurses to become competent in communicating in cross-cultural learning program and that the clinical learning environment provides them with the opportunity to put their learning into practice.

\section{ACKNOWLEDGEMENT}

Alhamdulillahirobbil `Aalamiin, my greatest gratitude for Allah S.W.T, the God who blesses me a beautiful life. My grateful thank also for my family, the Dean of Health Science Faculty and all of the University Leaders of University of Muhammadiyah Malang for the great supports

\section{REFERENCES}

Bradby H ( 2001), Communication, interpretation and translation. In Ethnicity and Nursing Practice (Culley L, Dyson S, eds.), Palgrave, Basingstoke, 129-48.

Browne S, Macdonald S, May CR, Macleod U, Mair FS (2014), Patient, Carer and Professional Perspectives on Barriers and Facilitators to Quality Care in Advanced Heart Failure. PLoS ONE 9(3): e93288. doi:10.1371/journal.pone.0093288. 
Cioffi R.N (2003), Communicating With Culturally and Linguistically Diverse Patients In an Acute Care Setting : Nurses' Experiences. Int J Nurs Stud ; 40: 299-306.

Charmaz, K. (2006), Constructing Grounded Theory, a Practical Guide Through Qualitative Analysis, Sage Publication Ltd, California, USA.

Gerrish K, Husband C, Mackenzie J (1996), Nursing for A Multi-ethnic Society, Open University Press, Buckingham.

Gerrish K.( 2001), The Nature and Effect of Communication Difficulties Arising From Interactions Between District Nurses and South Asian Patients And Their Carers. $J$ Adv Nurs; 33: 566-74.

Gerrish K, Chau R, Sobowale A, Birks E, (2004), Bridging the Language Barrier: The Use of Interpreters In Primary Care Nursing. Health Soc Care Community; 12: 407-13.

Giger, J.N (2017), Transcultural in Nursing Assessment and Intervention 7th Edition. Mosby Inc. St.Louise Missouri USA.

Hitchcock, Janice E. (1999), Community Health Nursing : Caring in Action, Albany,New York, Delmar Publisher.

Holloway, I. and S. Wheeler (2010), Qualitative Research in Nursing and Health Care, 3th Edition, Blackwell Publishing Ltd, Oxford, UK.

Kai J, Beavan J, Faull C, Dodson L, Gill P, Beighton A (2007), Professional uncertainty and disempowerment responding to ethnic diversity in health care: a qualitative study. PLoS Med ; 4: e323. 41.

Kai J, Bridgewater R, Spencer J ( 2001), Just think of TB and Asians', that's all I ever hear': medical learners' views about training to work in an ethnically diverse society. Med Educ; 35: 250-6.

Kieft R.AMM, de Brouwer B.BJM, Francke A.L, and Delnoij D.MJ (2014), How nurses and their work environment affect patient experiences of the quality of care: a qualitative study. BMC Health Services Research201414: 249 DOI: 10.1186/14726963-14-249.

Kratzke, C., Bertolo, M (2013), Enhancing Student's Cultural Competence Using CrossCultural Experiential Learning, Journal of Cultural Diversity, Retrieved from : https://www.researchgate.net/publication/258952956.

Leininger M, McFarland MR (2002), Transcultural Nursing: Concepts, Theories, Research and Practice, 3rd edn., McGraw-Hill Medical Pub. Division, New York.

Lincoln, Y. S. and E.G. Guba ( 1985), Naturalistic inquiry. Beverly Hills, CA: Sage.

Papadopoulos I, Tilki M, Taylor G (1998), Developing transcultural skills. In Transcultural Care : a Guide for Health Care Professionals (Papadopoulos I, Tilki M, Taylor G, eds.), Quay Books, Salisbury, 186-222.

Polit, D.F and C.T. Beck ( 2012), Nursing Research Generating and Assessing Evidence for Nursing Practice. $9^{\text {th }}$ Edition. Lippincot Williams and Wilkins. China.

Potter, P. A. and A. G. Perry ( 2008), Fundamentals of Nursing, $7^{\text {th }}$ Edition, Book and Clinical Companion, Mosby Inc. USA.

Seale C., Rivas C., and Kelly M (2013), The Challenge of Communication In Interpreted Consultations In Diabetes Care : a Mixed Methods Study. $\mathrm{Br} J$ Gen Pract 2013; 63 (607): e125-e133. DOI: https://doi.org/10.3399/bjgp13X663082

Shenton, A.K ( 2004), Strategies for Ensuring Trustworthiness in Qualitative Research Projects. Education for Information 222004 63-75 63 IOS Press. Available Source: http://www.angelfire.com/theforce/shu_cohort_viii/images/Trustworthypaper.pdf.

Straus, A. and J. Corbin (1998), Basics of Qualitative Research: Techniques and Procedures for Developing Grounded Theory, 2nd edn., Sage, Thousand Oaks, CA. 
Xiao D.L., Shen J., Paterson J (2013), Cross Cultural Comparison of Attitudes and Preferences for Care of The Elderly Among Australian and Chinese Nursing Students. Journal of Transcultural Nursing, 24(4):408-16. DOI : $10.1177 / 1043659613493329$. 